\title{
Mortality and causes of death among patients with opioid use disorder receiving opioid agonist treatment: a national register study
}

\author{
Anne Berit Bech ${ }^{1,2^{*}}$ (D), Thomas Clausen ${ }^{2}$, Helge Waal ${ }^{2,3}$, Jūratè Šaltyte Benth ${ }^{4,5}$ and Ivar Skeie ${ }^{2,6}$
}

\begin{abstract}
Background: Mortality rates and causes of death among individuals in opioid agonist treatment (OAT) vary according to several factors such as geographical region, age, gender, subpopulations, drug culture and OAT status. Patients in OAT are ageing due to effective OAT as well as demographic changes, which has implications for morbidity and mortality. Norway has one of the oldest OAT populations in Europe. Because of the varying mortality rates and causes of death in different subgroups and countries, research gaps still exist. The aims of this study were to describe the causes of death among OAT patients in Norway, to estimate all-cause and cause-specific crude mortality rates (CMRs) during OAT and to explore characteristics associated with drug-induced cause of death compared with other causes of death during OAT.
\end{abstract}

Methods: This was a national, observational register study. Data from the Norwegian Cause of Death Registry and the Norwegian Patient Registry were combined with data from medical records. We included all patients in the Norwegian OAT programme who died not more than 5 days after the last intake of OAT medication, between 1 January 2014 and 31 December 2015.

Results: In the 2-year observation period, 200 (1.4\%) of the OAT patients died. A forensic or medical autopsy was performed in $63 \%$ of the cases. The mean age at the time of death was 48.9 years (standard deviation 8.4 ), and $74 \%$ were men. Somatic disease was the most common cause of death (45\%), followed by drug-induced death (42\%), and violent death (12\%). In general, CMRs increased with age, and they were higher in men and in patients taking methadone compared with buprenorphine. Increasing somatic comorbidity, measured by the Charlson comorbidity index, reduced the odds of dying of a drug-induced cause of death compared with other causes of death.

Conclusions: Both somatic and drug-induced causes of death were common during OAT. Improved treatment and follow-up of chronic diseases, especially in patients aged $>40$ years, and continuous measures to reduce druginduced deaths appear to be essential to reduce future morbidity and mortality burdens in this population.

Keywords: Opioid agonist treatment, Mortality, Cause of death, Multimorbidity, Overdose, Methadone, Buprenorphine

\footnotetext{
* Correspondence: anne.bech@sykehuset-innlandet.no

${ }^{1}$ National Advisory Unit on Concurrent Substance Abuse and Mental Health

Disorders, Innlandet Hospital Trust, Department of Mental Health, P.O. Box

104, N-2381 Brumunddal, Norway

${ }^{2}$ Norwegian Centre for Addiction Research (SERAF), Institute of Clinical

Medicine, Oslo University, P.O. Box 1171, Blindern, N-0318 Oslo, Norway

Full list of author information is available at the end of the article
}

(c) The Author(s). 2019 Open Access This article is distributed under the terms of the Creative Commons Attribution 4.0 International License (http://creativecommons.org/licenses/by/4.0/), which permits unrestricted use, distribution, and reproduction in any medium, provided you give appropriate credit to the original author(s) and the source, provide a link to the Creative Commons license, and indicate if changes were made. The Creative Commons Public Domain Dedication waiver (http://creativecommons.org/publicdomain/zero/1.0/) applies to the data made available in this article, unless otherwise stated. 


\section{Background}

Opioid use disorder (OUD) is associated with high rates of morbidity and mortality [1]. Individuals who use illicit opioids have up to 15 times the risk of premature mortality compared with the general population [2]. Opioid agonist treatment (OAT) with methadone, buprenorphine or buprenorphine-naloxone is the most common evidence-based treatment modality for individuals with OUD. It is well established that OAT substantially reduces mortality, especially overdose deaths [1-4]. Criminal convictions and somatic morbidity related to substance use and drug injection (e.g., local and systemic bacterial infections) are also reduced during OAT, and quality of life is improved [1,5-7].

Mortality rates and causes of death among individuals in OAT vary according to factors such as geographical region, age, gender, subpopulations, cohort characteristics, drug culture (i.e., injection), retention in treatment and OAT status [2, 4]. A systematic review and metaanalysis published in 2018 found a pooled all-cause crude mortality rate (CMR) of 0.93 per 100 person-years (PY) (95\% confidence interval [CI]: 0.79-1.04) during OAT compared with 4.89/100 PY (CI 3.54-6.23) for untreated periods and 1.69/100 PY (CI 1.47-1.91) after cessation of OAT [4]. In general, CMRs increase with age, especially for somatic causes of death [8], and men have higher CMRs compared with women [2, 4]. CMRs also appear to be higher for individuals taking methadone compared with those taking buprenorphine during induction and treatment, and after cessation of OAT [24]. However, retention in treatment is better with methadone [9], and retention in OAT for more than 1 year is associated with a lower mortality rate [4].

OAT patients in Europe are ageing due to effective OAT as well as demographic changes as the post-war baby boom generation ages [10]. This ageing trend can also be seen in Australia and in the USA [10, 11], and has implications for morbidity and mortality. Norway has one of the oldest OAT populations in Europe [12], with a mean age of 44.9 years in 2017 [13]. As OAT patients are getting older, somatic causes of death will likely increase [14], although high drug-induced mortality, irrespective of gender, has been found among ageing methadone patients in recent studies from Scotland and England, including high methadone-specific mortality rates in patients aged $>45$ years $[15,16]$.

Research gaps still exist because of varying mortality rates and causes of death in different subgroups and countries. In Norway, mortality data on individuals receiving OAT are more than 10 years old $[8,17]$, and no recent studies have linked data to the mortality register [14], which is essential to obtain reliable data about the causes of death. To improve treatment and prevent premature mortality, more research is warranted to better understand mortality rates and the distribution of causes of death in an ageing OAT population. The aims of this study were to describe the causes of death among OAT patients in Norway, to estimate all-cause and causespecific CMRs during OAT in patients stratified by age, OAT medication and gender, and to explore characteristics associated with drug-induced cause of death compared with other causes of death during OAT.

\section{Methods}

\section{Study design and setting}

This study was a national, observational study combining register and hospital record data. In Norway, OAT is delivered within a national OAT programme and encompasses both abstinence-oriented treatment and harm-reduction goals. Addiction units in the specialist health care system assess the need for OAT and initiate treatment, and the treatment involves collaboration between addiction units, general practitioners (GPs) and health and social services in the municipalities $[18,19]$. At the end of 2017, 7622 patients were enrolled in OAT, $38 \%$ of whom used methadone and $59 \%$ used buprenorphine or buprenorphine-naloxone [13].

We included all patients in the national OAT programme who died between 1 January 2014 and 31 December 2015. According to the national guidelines, patients who have missed doses for more than 5 consecutive days must be restarted on OAT medication because of potential loss of opioid tolerance. Thus, patients were included if they had died during ongoing treatment or not more than 5 days after the last reported intake of OAT medication. Clinicians in addiction units initially reported 255 deceased OAT patients. Fifty-five patients were excluded: 44 patients who died more than 5 days after the last reported intake of OAT medication, eight patients whom the hospitals were unable to identify further and three patients whose OAT status was unknown at the time of death. A total of 200 patients met the inclusion criteria.

\section{Measurements}

Data from the Norwegian Cause of Death Registry and the Norwegian Patient Registry (NPR) were combined with hospital record data. Clinicians completed a questionnaire about the patient's age, gender, health region, OAT medication at the time of death, duration of OAT treatment and information about prescription drugs used before death. At least one prescription of benzodiazepines (BZD) or z-hypnotics during the year before death registered either in the questionnaire or in the medical record was dichotomized into one variable called "BZD/z-hypnotic medication". At least one prescription of antidepressants and/or antipsychotic drugs was dichotomized into one variable called "Psychotropic 
medication". From the hospital records, we also collected the OAT status report for the year of death and 3 years before death, if available. The OAT status report is an annual individual report on all OAT patients and is based on the clinician's knowledge of the patient's situation; this report is preferably completed in collaboration with the patient. The variables "Disability/ retirement pension", "Own home" and "OAT prescribed by GPs" were collected from the OAT status reports.

Data on the cause of death, place of death, main intoxicant in drug-induced deaths and whether the deceased had an autopsy or not were obtained from the Norwegian Cause of Death Registry [20]. The underlying cause of death is defined as "the illness or injury which initiated the train of morbid events leading directly to death or the circumstances of the accident or violence which produced the fatal injury" [21]. The underlying cause of death was categorized into one of three main groups: death due to somatic disease, drug-induced death and violent death. The definition of drug-induced death is based on the International Classification of Diseases, 10th edition (ICD-10) and includes unintentional overdose or overdose by unknown intent, intentional overdose and substance use disorder [21, 22]. Violent deaths include deaths due to accident, suicide (except intentional overdose) and homicide.

The NPR contains information about all patients referred to or having received treatment in the specialist health care service in Norway [23]. From the NPR, we collected information on admissions to psychiatric hospitals and the diagnoses based on the ICD-10 in the 5 years before death. For each patient, we derived a Charlson comorbidity index score, which is a widely used measure of disease burden based on age and ICD-10 diagnoses for 17 somatic conditions [21, 24, 25]. The variable "Previous non-fatal overdose(s)" refers to either non-fatal overdoses registered in the OAT status report or hospital admission due to non-fatal intoxication (ICD-10 codes T4n, T50.9 and T56.9) registered in the NPR in the 5 years before death.

Data were collected in 2017 and 2018; however, to minimize recall bias, the questionnaire used in the study was filled out by the clinicians shortly after the patients had died in 2014 and 2015. In six cases, the cause of death was not registered or was unknown in the Cause of Death Registry but was found in the medical records. Thus, the cause of death could not be established in only two of 200 patients.

\section{Statistical analysis}

The characteristics of all patients and stratified by causes of death were described by frequencies and percentages if categorical, and means and standard deviations (SD) or medians and minimum and maximum values if continuous. Group comparisons were made using Student's $t$ test or Mann-Whitney $U$ test for continuous data and $x^{2}$ or Fisher's exact test for categorical data. To obtain more balanced CMRs, data for the years 2014 and 2015 were combined due to the small number of expected deaths. The CMRs were calculated by dividing the total number of deaths in OAT by the total number of patients in OAT mid-year 2014 and 2015 (i.e., PY), for all patients as well as stratified by age, OAT medication and gender. CMRs are reported per 100 PY, with 95\% Poisson CIs [26]. Bivariate and multiple multilevel regression models were estimated to assess the association between drug-induced cause of death and patient characteristics included as fixed effects into the models. Random intercepts for region were included to correctly adjust the estimates for within-region correlations. The results are presented as odd ratios (ORs) and 95\% CIs, with other causes of death used as reference category. The regression models were estimated on cases with no missing values of covariates. The results with $p<0.05$ were considered statistically significant, and all tests were two-sided. The analyses were performed using IBM SPSS Statistics for Windows version 25 (IBM Corp.), Stata Statistical Software version 15 (StataCorp LLC) and SAS version 9.4.

\section{Ethical considerations}

The study was approved by the Regional Committee for Medical and Health Research Ethics South-East (Case number 2016/1204), the Cause of Death Registry, the NPR and the participating hospital trusts, including data protection officials.

\section{Results}

\section{Patient characteristics}

Table 1 gives an overview of the patient characteristics. The mean age at the time of death was 48.9 years (SD 8.4 , ranging from 23 to 71 years), and $74 \%(n=147)$ were men. Methadone was used by $55 \%$ of patients, at a median dose of $90 \mathrm{mg}$ (ranging from 15 to $200 \mathrm{mg}$ ), and buprenorphine was used by $41 \%$ at a median dose of 16 $\mathrm{mg}$ (ranging from 1 to $52 \mathrm{mg}$ ). GPs prescribed OAT medication for $68 \%(n=156)$ of the patients. The median total duration of OAT was 8 years (ranging from 1 month to 17 years). Four patients had been in OAT for $<3$ months at the time of death.

Comorbid conditions were common, as reflected by a median Charlson comorbidity index score of 2 . Only $18 \%$ of the patients had a Charlson comorbidity index of zero, which corresponds to no registered somatic medical condition in the NPR and aged $<50$ years at the time of death. The most frequent chronic diseases registered in the NPR in the 5 years before death were liver diseases (62\%, chiefly hepatitis C), 
Table 1 Characteristics of 200 patients who died during opioid agonist treatment, stratified by the cause of death

\begin{tabular}{|c|c|c|c|c|}
\hline \multirow[t]{2}{*}{ Variables } & \multirow[t]{2}{*}{$\mathrm{N}$} & \multirow[t]{2}{*}{ Total, N (\%) } & \multirow{2}{*}{$\begin{array}{l}\text { Drug-induced deaths } \\
N=84, \mathrm{n}(\%)\end{array}$} & \multirow{2}{*}{$\begin{array}{l}\text { All other causes of death } \\
N=116, \mathrm{n}(\%)\end{array}$} \\
\hline & & & & \\
\hline \multicolumn{5}{|l|}{ Demographics } \\
\hline Male gender & 200 & $147(74)$ & $59(70)$ & $88(76)$ \\
\hline Age, mean (SD) & 200 & $48.9(8.4)$ & $46.9(8.5)$ & $50.3(8.2)$ \\
\hline Region East, & 200 & $89(45)$ & $30(36)$ & $59(51)$ \\
\hline \multicolumn{5}{|l|}{ incl. Capital Oslo } \\
\hline Region South & 200 & $39(20)$ & $16(19)$ & $23(41)$ \\
\hline Region West & 200 & $44(22)$ & $26(31)$ & $18(16)$ \\
\hline Region Mid-Norway & 200 & $14(7)$ & $7(8)$ & $7(6)$ \\
\hline Region North & 200 & $14(7)$ & $5(6)$ & $9(8)$ \\
\hline Disability/retirement pension ${ }^{a}$ & 154 & $117(76)$ & $45(70)$ & $72(80)$ \\
\hline Own home ${ }^{b}$ & 162 & $125(77)$ & $54(78)$ & $71(76)$ \\
\hline \multicolumn{5}{|l|}{ OAT medication } \\
\hline Methadone & 199 & $109(55)$ & $46(55)$ & $63(54)$ \\
\hline Buprenorphine & 199 & $82(41)$ & $35(42)$ & $47(41)$ \\
\hline Other & 199 & $8(4)$ & $2(2)$ & $6(5)$ \\
\hline OAT prescribed by GPs & 156 & $106(68)$ & $42(60)$ & $64(74)$ \\
\hline \multicolumn{5}{|c|}{ Dose methadone (met) or buprenorphine (bup) } \\
\hline$<60$ mg met or $<8$ mg bup & 187 & $21(11)$ & $10(12)$ & $11(10)$ \\
\hline $60-120$ mg met or 8-24 mg bup & 187 & $141(75)$ & $62(77)$ & $79(75)$ \\
\hline$>120$ mg met or $>24$ mg bup & 187 & $25(13)$ & $9(11)$ & $16(15)$ \\
\hline \multicolumn{5}{|l|}{ Total duration of OAT } \\
\hline$<4$ years & 188 & $36(19)$ & $14(18)$ & $22(20)$ \\
\hline $4-8$ years & 188 & $56(30)$ & $30(38)$ & $26(24)$ \\
\hline $8-12$ years & 188 & $49(26)$ & $18(23)$ & $31(29)$ \\
\hline $12-17$ years & 188 & $47(25)$ & $18(23)$ & $29(27)$ \\
\hline \multicolumn{5}{|l|}{ Comorbidities } \\
\hline Charlson index score, & 200 & $2.0(0-12)$ & $1.0(0-9)$ & $3.0(0-12)$ \\
\hline \multicolumn{5}{|l|}{ median (min-max) } \\
\hline Psychiatric admissions $^{c}$ & 200 & $56(28)$ & $26(31)$ & $30(26)$ \\
\hline BZD/Z-hypnotics ${ }^{d}$ & 177 & $76(43)$ & $28(38)$ & $48(46)$ \\
\hline Psychotropic medication ${ }^{\mathrm{e}}$ & 156 & $44(28)$ & $12(20)$ & $32(33)$ \\
\hline Previous non-fatal overdose $e^{f}$ & 200 & $59(30)$ & $30(36)$ & $29(25)$ \\
\hline
\end{tabular}

${ }^{a}$ Only four patients had a retirement pension at the time of death ( $>67$ years). Among those who did not have a disability or retirement pension, two had paid work and the rest had work assessment allowance or social welfare

${ }^{b}$ Own home, rented or owned. Among those who did not have an own home, two were homeless; the rest lived in shelters, institutions, with friends/family or were in prison

${ }^{C}$ Psychiatric admissions registered in the NPR in the last 5 years before death

${ }^{\mathrm{d} B Z D / Z-h y p n o t i c s ~ p r e s c r i b e d ~ a t ~ l e a s t ~ o n c e ~ i n ~ t h e ~ y e a r ~ b e f o r e ~ d e a t h ~}$

${ }^{\mathrm{e}}$ Antidepressants/antipsychotic medication prescribed at least once in the year before death

${ }^{f}$ Non-fatal overdoses registered in the NPR or in OAT status reports in the last 5 years before death

cardio-vascular diseases (19\%) and chronic obstructive pulmonary disease (COPD) (19\%). Co-prescription was common, and $43 \%$ of the deceased had at least one prescription of $\mathrm{BZD} / \mathrm{z}$-hypnotics in the year before death, and $28 \%$ were prescribed other psychotropic medication. Thirty per cent of the patients had experienced previous non-fatal overdose(s) in the last 5 years before death.

Compared with patients taking buprenorphine, patients taking methadone were significantly more likely to live in Health Region East than the other four health regions $(75 \%$ vs. $61 \% / 31 \% / 29 \% / 46 \%$; all $p<0.01)$ and they 
had been significantly longer in OAT (median 10.1 vs. 6.8 years; $p<0.001$ ), but were not significantly older (mean 49.3 vs. 48.1 years; $p=0.331$ ) (data not shown in Table 1).

\section{Causes of death}

Table 2 provides an overview of the causes of death for all patients as well as stratified by gender; 90 deaths (45\%) were caused by somatic disease, $84(42 \%)$ were drug induced, and 23 (12\%) were violent deaths.

Cancer and cardio-vascular and pulmonary diseases were the most frequent somatic causes of death. Twenty-six patients died of cancer, and lung cancer alone accounted for one-third of cancer fatalities. COPD, emphysema and pneumonia were the most frequent causes of death for those who died of pulmonary diseases. Cardio-vascular causes of death were more diverse, involving pulmonary embolism, haemorrhagic stroke, endocarditis, chronic ischaemia or myocardial infarction. Among the 14 patients who died of a liver disease, one died of liver cancer. The group "Other somatic cause of death" included four cases of kidney failure, three of diabetes, two of gastrointestinal bleeding, two of bacterial infections/sepsis and one case of epilepsy. Seven patients had a confirmed secondary amyloidosis (amyloid A [AA] amyloidosis) diagnosis with end-stage kidney disease and needed regular haemodialysis, but only two of them had kidney failure as the underlying cause of death. Bacterial infections contributed substantially to mortality: 30 patients (15\%) had bacterial infections either as a contributing cause or as an underlying cause of death in the Cause of Death Registry. The most common infections were pneumonia, endocarditis or fatal sepsis. Nine patients (5\%) had human immunodeficiency virus (HIV), but no patients died of acquired immune deficiency syndrome (AIDS).

Several patients had more than one potential fatal somatic disease documented in medical records or in the Cause of Death Registry. Two fatalities exemplified the complex of multiple comorbidities: one involved chronic hepatitis B and C, AA amyloidosis with endstage kidney failure, COPD and death due to overdose; the other involved chronic hepatitis B and C, HIV, COPD, acute liver and kidney failure and death due to respiratory failure.

Among the 84 drug-induced deaths, 71 patients had undergone an autopsy. In the Cause of Death Registry, methadone was reported as the main intoxicant in 31 deaths and heroin in 17. Other opioids, including buprenorphine, were the reported main intoxicant in an

Table 2 Causes of death among 200 patients in opioid agonist treatment in Norway, stratified by gender

\begin{tabular}{|c|c|c|c|}
\hline & Total & Men & Women \\
\hline & $N=200, \mathrm{n}(\%)$ & $N=147, \mathrm{n}(\%)$ & $N=53, \mathrm{n}(\%)$ \\
\hline Somatic cause of death & $90(45)$ & $69(47)$ & $21(40)$ \\
\hline Cancer, excl. Liver cancer & $26(29)$ & $19(28)$ & $7(33)$ \\
\hline Cardio-vascular disease & $20(22)$ & $15(22)$ & $5(24)$ \\
\hline Pulmonary disease & $18(20)$ & $14(20)$ & $4(19)$ \\
\hline Liver disease, incl. Liver cancer & $14(16)$ & $12(17)$ & $2(10)$ \\
\hline Other somatic cause of death & $12(13)$ & $9(13)$ & $3(14)$ \\
\hline Drug-induced cause of death ${ }^{a}$ & $84(42)$ & $59(40)$ & $25(47)$ \\
\hline Methadone & $31(37)$ & $21(36)$ & $10(40)$ \\
\hline Heroin & $17(20)$ & $14(24)$ & $3(12)$ \\
\hline Other opioids (T402, T404, T406) & $15(18)$ & $10(17)$ & $5(20)$ \\
\hline Substance use disorder (F11, F19) & $17(20)$ & $11(19)$ & $6(24)$ \\
\hline Non-opioid overdose & $4(5)$ & $3(5)$ & $1(4)$ \\
\hline Violent cause of death & $23(12)$ & $16(11)$ & $7(13)$ \\
\hline Suicide & $12(52)$ & $7(44)$ & $5(71)$ \\
\hline Accident & $8(35)$ & $6(38)$ & $2(29)$ \\
\hline Homicide & $3(13)$ & $3(19)$ & 0 \\
\hline Other/unknown cause of death ${ }^{\mathrm{b}}$ & $3(2)$ & $3(2)$ & 0 \\
\hline
\end{tabular}

Data are expressed as $n$ (\%). The distributions of somatic cause of death, drug-induced, violent and unknown cause of death did not differ between men and women $\left(p=0.610^{\mathrm{a}}\right)$

aFive suicides by intentional overdose are included in the group "Drug-induced death". Only four patients < 31 years died during OAT; all four died of overdose bone patient with non-organic psychosis (F29) as the cause of death was included in the group "Other/unknown cause of death" 
additional 15 deaths. No drug-induced deaths occurred in the first month after initiation of methadone or buprenorphine. Ten of the 17 patients with substance use disorder as an underlying cause of death had severe medical comorbidities as a contributing cause of death in the Cause of Death Registry.

Half of the violent deaths were suicides, and threequarters of the suicides were intentional self-harm by hanging. Both men and women died in suicides and accidents (falling, hypothermia, fire and traffic accidents), but all three homicide victims were men.

Forensic or medical autopsies were performed for 125 (63\%) of the deaths. The autopsy rate was high for all unnatural deaths: $66 \%$ for suicides, $85 \%$ for druginduced deaths, $88 \%$ for accidents and $100 \%$ for homicides. The most common place of death was the home address $(43 \%)$, where almost two-thirds of the deaths were drug-induced; $37 \%$ died in a hospital or other health institution, three-quarters of whom died of an already known somatic disease. We found no statistically significant differences between men and women in the causes of death, autopsy rates or place of death.

\section{CMRs}

Table 3 shows that the mean number of patients in OAT was 7220 in 2014 and 7439 in 2015, giving a total observation period of 14,659 PY. The 2-year all-cause CMR during OAT was $1.4 / 100$ PY (equivalent to $1.4 \%$ ). In general, CMRs increased with age. The mortality rate for somatic causes of death was twice as high in patients aged $>50$ years than in those aged $41-50$ (mortality rate ratio [MRR] 2.1, CI 1.3-3.4). The rates for drug-induced deaths also increased with age, although not as steeply as those for somatic causes of death, whereas the rates for violent deaths were the same across all age groups. Men had a slightly higher mortality rate than women (MRR 1.2, CI 0.5-0.9). The mortality rate was twice as high among patients taking methadone than among those taking buprenorphine (MRR 2.0, CI 1.5-2.7).

\section{Characteristics associated with drug-induced cause of death during OAT}

Table 4 shows the results from a multilevel logistic regression analysis assessing characteristics associated with drug-induced cause of death compared with all other causes of death during OAT. In bivariate analyses, both increasing age $(p<0.05)$ and increasing Charlson comorbidity index score $(p<0.001)$ were associated with lower odds of dying of a drug-induced cause of death. In the multiple model, only the Charlson comorbidity index remained significant $(p<0.001)$. The variables of male gender, taking methadone (compared with taking buprenorphine), previous non-fatal overdoses, psychiatric admissions and duration of OAT were not associated with dying of a drug-induced cause of death during OAT, neither in the bivariate nor in the multiple analyses.

\section{Discussion}

In this study on mortality in the total Norwegian OAT population, both somatic and drug-induced causes of death were frequent during OAT. In the 2-year observation period, $1.4 \%$ of the patients died. In general, CMRs increased with age, and this pattern was more pronounced for somatic causes than other causes of death.

Table 3 CMRs/100 PY (95\% CI) during OAT, stratified by age, OAT medication and gender

\begin{tabular}{|c|c|c|c|c|c|c|}
\hline & PY in OAT (\%) & $\begin{array}{l}\text { Deaths, } \\
\text { n (\%) }\end{array}$ & CMR/100 PY (95\% Cl) & Drug-induced cause of death & Somatic cause of death & $\begin{array}{l}\text { Violent cause } \\
\text { of death }\end{array}$ \\
\hline 2014 & 7220 & $95(48)$ & $1.3(1.1-1.6)$ & NA & NA & NA \\
\hline 2015 & 7439 & $105(52)$ & $1.4(1.2-1.7)$ & NA & NA & NA \\
\hline Total & 14,659 & 200 & $1.4(1.2-1.6)$ & $0.6(0.5-0.7)$ & $0.6(0.5-0.8)$ & $0.2(0.1-0.2)$ \\
\hline \multicolumn{7}{|l|}{ Age } \\
\hline$<41$ years & $5570(38)$ & $33(17)$ & $0.6(0.4-0.8)$ & $0.3(0.2-0.5)$ & $0.1(0.1-0.2)$ & $0.2(0.1-0.3)$ \\
\hline $41-50$ years & $5424(37)$ & $81(41)$ & $1.5(1.2-1.9)$ & $0.7(0.5-0.9)$ & $0.7(0.5-0.9)$ & $0.2(0.1-0.3)$ \\
\hline$>50$ years & $3665(25)$ & $86(43)$ & $2.4(1.9-2.9)$ & $0.8(0.6-1.2)$ & $1.4(1.0-1.8)$ & $0.1(0.0-0.3)$ \\
\hline \multicolumn{7}{|l|}{ OAT medication } \\
\hline Methadone & $5707(39)$ & $109(55)$ & $1.9(1.6-2.3)$ & $0.8(0.6-1.1)$ & $0.9(0.7-1.2)$ & $0.2(0.1-0.4)$ \\
\hline Buprenorphine & $8487(58)$ & $82(41)$ & $1.0(0.8-1.2)$ & $0.4(0.3-0.6)$ & $0.4(0.3-0.6)$ & $0.1(0.1-0.2)$ \\
\hline \multicolumn{7}{|l|}{ Gender } \\
\hline Male & $10,261(70)$ & $147(73)$ & $1.4(1.2-1.7)$ & $0.6(0.4-0.7)$ & $0.7(0.5-0.9)$ & $0.2(0.1-0.3)$ \\
\hline Female & $4398(30)$ & $53(27)$ & $1.2(0.9-1.6)$ & $0.6(0.4-0.8)$ & $0.5(0.3-0.7)$ & $0.2(0.1-0.3)$ \\
\hline
\end{tabular}

CMR crude mortality rate, $P Y$ person-years, $C l$ confidence interval, OAT opioid agonist treatment, NA not applicable

Causes of death $n=197$, three patients with other/unknown cause of death excluded

OAT medication $n=191$, other OAT medication excluded. This represents the use of OAT medication at the time of death. We could not obtain information about the changes in OAT medication before death 
Table 4 Results of multilevel logistic regression analysis for characteristics associated with drug-induced cause of death during $O A T^{a}$

\begin{tabular}{lll}
\hline $\begin{array}{ll}\text { Characteristics } \\
\text { Gender }\end{array}$ & $\begin{array}{l}\text { Bivariate models } \\
\text { OR }(95 \% \mathrm{Cl})\end{array}$ & $\begin{array}{l}\text { Multiple model } \\
\text { OR }(95 \% \mathrm{Cl})\end{array}$ \\
$\begin{array}{l}\text { Men } \\
\text { Women }\end{array}$ & 1 & 1 \\
Age & $1.37(0.70 ; 2.70)$ & $1.59(0.77 ; 3.30)$ \\
OAT medication & $0.95(0.92 ; 0.99)^{*}$ & $0.99(0.95 ; 1.04)$ \\
$\quad$ Buprenorphine & 1 & \\
$\quad$ Methadone & $1.24(0.64 ; 2.41)$ & $1.25(0.63 ; 2.48)$ \\
Charlson index & $0.73(0.62 ; 0.85)^{* *}$ & $0.72(0.61 ; 0.86)^{* *}$ \\
Non-fatal overdoses & & \\
No & 1 & 1 \\
Yes & $1.60(0.83 ; 3.10)$ & $1.72(0.82 ; 3.60)$ \\
Psychiatric admissions & & 1 \\
No & 1 & $0.91(0.44 ; 1.88)$ \\
Yes & $1.35(0.70 ; 2.60)$ & $1.00(0.92 ; 1.08)$ \\
OAT total duration in years & $0.97(0.90 ; 1.04)$ &
\end{tabular}

OAT opioid agonist treatment. Only complete cases are included, $N=181$. ${ }^{*} p<0.05,{ }^{* *} p<0.001$

aThe reference category is "Other causes of death"

${ }^{b}$ Non-fatal overdoses registered in the NPR or in OAT status reports in the last 5 years before death

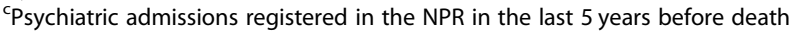

The CMR was also higher in patients taking methadone compared with buprenorphine. In the multiple regression model, we found that increasing somatic comorbidity, as measured by the Charlson comorbidity index, reduced the odds of dying of a drug-induced cause of death compared with other causes of death.

In line with previous Norwegian studies, we found that somatic causes of death among OAT patients predominated $[8,17]$. Non-communicable diseases such as cancer and COPD take time to develop and are associated with both age and the lifestyle factors prevalent among OAT patients. High rates of pulmonary diseases and increased cancer risk are consistent with previous findings in ageing OAT patients [27-31]. COPD and emphysema are independent risk factors for lung cancers, together with smoking, and predict reduced survival [32, 33]. Liver cirrhosis and liver cancer due to hepatitis $C$ also contribute substantially to morbidity and mortality among opioid users [34]; however, despite a high prevalence of hepatitis $\mathrm{C}$ among the deceased in our study, only 14 patients died of liver disease. Some of the deaths of somatic origin were probably more directly associated with injecting drug use. Acute bacterial skin and soft tissue infections are common among injecting drug users [35], and bacteraemia often causes severe focal infections and sepsis. Persisting infections and inflammation caused by continued injecting and skin popping (subcutaneous injecting) are also associated with AA amyloidosis [36, 37]. AA amyloidosis was not encountered among heroin users in Norway until 2005 [37] but is now an emerging issue among the ageing OAT patients. Injection-related health risks other than blood-borne viral infections in OAT patients who continue to use drugs might be an under-researched topic.

Although the overdose risk is reduced during OAT, nevertheless $42 \%$ of the patients in our study had a drug-induced cause of death. None of the patients died of an overdose in the first month after initiating OAT. The increased risk of fatal overdose during initiation of methadone may vary according to treatment setting [4, 38]. According to Norwegian OAT guidelines, both buprenorphine and methadone should be initiated under monitoring and observation, and inpatient detoxification at the initiation of OAT is common [19]. Methadone was judged to be the main intoxicant in 31 of the 84 drug-induced deaths and, in all except two cases, the patient was taking methadone as the OAT medication. The interpretation of this finding is not straightforward. It is difficult to determine the precise role of OAT medication in fatal overdoses [39]. The instituted dose of methadone may become dangerous because of increasing vulnerability as OAT patients age and comorbidity levels rise. The overdose risk among OAT patients is associated with several factors such as somatic and psychiatric comorbidities, co-prescribing, previous non-fatal overdoses and polydrug use [40-42], which may make it difficult to ascertain the exact cause of death. In addition, the post-mortem examiner is not always informed about the OAT status. Thus, the number of methadone deaths might represent an overestimation, and may in fact have been caused by single or multiple somatic causes in combination with regular prescribed methadone doses.

An all-cause mortality rate of 1.4/100 PY during OAT was the same as found in an earlier Norwegian study [17], but higher than the rate of $0.93 / 100$ PY found in a systematic review and meta-analysis [4]. In line with previous studies, CMRs increased with age, and were higher in men and for patients taking methadone compared with buprenorphine $[2-4,8]$. Suggested explanations for increased CMRs among patients taking methadone are methadone-induced prolongation of the QTc interval, increasing the risk of ventricular cardiac arrhythmia (torsades de pointes) and "sudden death", ingestion of alcohol and BZD, physical comorbidities and harder-tosupport patients $[15,16]$. In the Norwegian setting, the difference in CMRs might be explained by a "veteran effect". Until 2001, methadone was the only OAT medication. Patients taking methadone in our study had been treated in OAT for significantly longer than those taking 
buprenorphine, and most likely had a longer drug career. In addition, patients with a severe or terminal disease such as cancer taking buprenorphine are often converted to methadone or other opioids.

In the regression analysis, we found an association between increased somatic morbidity and reduced odds of a drug-induced cause of death. The Charlson comorbidity index was moderately correlated with age, which could be one explanation why age did not remain significant in the multiple model. Multimorbidity (i.e., having two or more chronic diseases) is associated with increased risk of mortality, functional decline, polypharmacy, increased number of hospital admissions and poorer quality of life [43]. Multimorbidity usually increases with age [43], but patients in OAT have high rates of chronic diseases across all age groups $[44,45]$. Several of the patients in our study had multiple severe and potentially fatal medical conditions, and thus several competing disease end-points.

Somewhat surprisingly, given the superior safety profile of buprenorphine, we did not find that taking methadone increased the odds of drug-induced cause of death compared with buprenorphine. The lack of association between the other covariates and drug-induced cause of death could be because the two groups were quite similar, which makes differences less likely to detect. Risk factors not included in the model (e.g., prescription medication, drug use) could be another explanation.

Our findings have several implications. Multimorbidity in OAT patients calls for a broad range of patientoriented and organizational measures, such as improved treatment and follow-up of chronic diseases and multidisciplinary teamwork and co-ordination of care [43, 44]. The high prevalence of COPD and pulmonary cancer suggests that a stronger focus on tailored tobacco harm-reduction approaches and smoking cessation is important for this patient group, and as early in their lives as possible, to reduce cumulative risk. OAT patients should be offered spirometry and lung image tests $[32,33]$. Overdose prevention is a multifaceted challenge [14]. Further measures may include improved follow-up after non-fatal overdose, reviewing older patients' methadone dosage in the context of somatic comorbidities (e.g., reduced liver and kidney function) and offering regular electrocardiograms to patients aged $>45$ years. Distribution of intranasal naloxone to at-risk populations is also relevant $[15,46,47]$.

\section{Strengths and limitations}

The strengths of our study include the use of register data that were combined with information from hospital medical records. This gave in-depth information about the fatalities that were not accessible using register data alone. The national OAT programme is organized within the public specialist health care service in Norway, and has a monopoly of this treatment modality; thus, we were able to study mortality in a complete, national OAT population. The high rate of forensic or medical autopsy also strengthens the validity of the findings. A valid cause of death was not established in only two patients (1\%).

Our study has several limitations. Almost half (47\%) of the questionnaires were completed by clinicians other than physicians, who do not always have access to somatic medical records. Thus, we cannot rule out the possibility of information bias. Regarding somatic comorbidity, we have no data on smoking status, but the smoking prevalence among Norwegian OAT patients is high and similar to the $69-94 \%$ prevalence reported in earlier studies [27, $45,48,49]$. In addition, the number of non-fatal overdoses is probably under-estimated, because most overdoses in Norway are attended by the ambulance service only. A higher number of participants would have allowed for more variables in the regression analysis. We did not have information on the changes in variables that can vary over time, such as prescription of BZD, psychotropic medications and changes in OAT medication before death. The broad categories of prescribed medication (at least one prescription of benzodiazepine and psychotropic medication in the year before death) limited their use as covariates in the regression analyses.

\section{Conclusions}

In this study on mortality among patients in the Norwegian OAT programme, both somatic and drug-induced causes of death were common during OAT. AA amyloidosis is an emerging issue. As expected, CMRs increased with age, and this increase was steeper for somatic causes than for other causes of death. CMRs were also higher in men and in patients taking methadone. Increasing somatic comorbidity reduced the odds of a drug-induced cause of death. Both improved treatment and follow-up of chronic diseases, especially in patients aged $>40$ years, and continuous measures to reduce drug-induced deaths appear to be essential to reduce future morbidity and mortality burdens in this population.

\section{Abbreviations \\ AA: Amyloid A; AIDS: Acquired immune deficiency syndrome; BZD: Benzodiazepines; Cl: Confidence interval; CMR: Crude mortality rate; COPD: Chronic obstructive respiratory disease; GP: General Practitioner; HIV: Human immune deficiency virus; ICD-10: International Classification of Diseases, 10th edition; MRR: Mortality rate ratio; NPR: Norwegian Patient Registry; OAT: Opioid agonist treatment; OR: Odds ratio; OUD: Opioid use disorder; PY: Person-years; SD: Standard deviation}

\section{Acknowledgements}

We thank Magne Thoresen, Oslo Centre for Biostatistics and Epidemiology, University of Oslo for statistical advice, and colleagues for support. We also thank all participating hospital trusts for their assistance with data collection: University Hospital of North Norway, Nordland Hospital Trust, Nord-

Trøndelag Hospital Trust, St. Olav's Hospital-Trondheim University Hospital, 
Møre og Romsdal Hospital Trust, Førde Hospital Trust, Bergen Hospital Trust, Stavanger Hospital Trust, Fonna Hospital Trust, Telemark Hospital Trust, Sørlandet Hospital Trust, Vestfold Hospital Trust, Vestre Viken Hospital Trust, Akershus University Hospital, Oslo University Hospital, Innlandet Hospital Trust, Østfold Hospital Trust and Lovisenberg Diaconal Hospital.

\section{Authors' contributions}

ABB participated in the detail planning of the study, collected the data, conducted the analysis together with and under supervision of IS and TC, and drafted, wrote and revised the manuscript. TC took part in the planning and designing of the study, was co-supervisor, consecutively commented on data analysis and revised the manuscript. HW took part in the original planning of the study and revised the manuscript. JBS has performed statistical analyses including multilevel logistic regression model, contributed with interpretation and description of results and critical input to the manuscript. IS was project leader and main supervisor, planned and designed the study and took part in the writing and revision of the manuscript. All authors read and approved the final manuscript.

\section{Funding}

The study was funded by Innlandet Hospital Trust (grant no. 150351). The funder had no involvement in the design of the study or in the collection, analysis and interpretation of data or in the writing of the manuscript.

\section{Availability of data and materials}

The dataset generated and analysed during the current study is not publicly available to protect the privacy of participants but it is available from the corresponding author on reasonable request.

\section{Ethics approval and consent to participate}

This study was approved by the Regional Committee for Medical and Research Ethics South-East (Case number 2016/1204), the Cause of Death Registry (Norwegian Institute of Public Health), the Norwegian Patient Registry (Norwegian Directorate of Health) and the participating hospital trusts, including data protection officials.

\section{Consent for publication}

Not applicable.

\section{Competing interests}

The authors declare that they have no competing interests.

\section{Author details}

${ }^{1}$ National Advisory Unit on Concurrent Substance Abuse and Mental Health Disorders, Innlandet Hospital Trust, Department of Mental Health, P.O. Box 104, N-2381 Brumunddal, Norway. ${ }^{2}$ Norwegian Centre for Addiction Research (SERAF), Institute of Clinical Medicine, Oslo University, P.O. Box 1171, Blindern, N-0318 Oslo, Norway. ${ }^{3}$ National Advisory Unit on Substance Use Disorder Treatment, Oslo University Hospital, Sognsvannsveien 21, Bygg 6, P.O. Box 4959 Nydalen, N-0424 Oslo, Norway. ${ }^{4}$ Institute of Clinical Medicine, Campus Ahus, Oslo University, P.O. Box 1171, Blindern, N-0318 Oslo, Norway. ${ }^{5}$ Health Services Research Unit, Akershus University Hospital, P.O. Box 1000, N-1478 Lørenskog, Norway. ${ }^{6}$ Regional Psychiatric Centre Gjøvik, Innlandet Hospital Trust, Kyrre Grepps gate 11, N-2819 Gjøvik, Norway.

Received: 27 April 2019 Accepted: 19 June 2019

Published online: 02 July 2019

\section{References}

1. World Health Organization. Guidelines for the psychosocially assisted pharmacological treatment of opioid dependence. 2009. http://www.who. int/substance_abuse/activities/treatment_opioid_dependence/en/. Accessed 10 April 2019

2. Degenhardt L, Bucello C, Mathers B, Briegleb C, Ali H, Hickman M, et al. Mortality among regular or dependent users of heroin and other opioids: a systematic review and meta-analysis of cohort studies. Addiction. 2011; 106(1):32-51.

3. Sordo L, Barrio G, Bravo MJ, Indave BI, Degenhardt L, Wiessing L, et al. Mortality risk during and after opioid substitution treatment: systematic review and meta-analysis of cohort studies. BMJ. 2017;357:j1550.
4. Ma J, Bao YP, Wang RJ, Su MF, Liu MX, Li JQ, et al. Effects of medicationassisted treatment on mortality among opioids users: a systematic review and meta-analysis. Mol Psychiatry. 2018. https://doi.org/10.1038/s41380-0180094-5.

5. Bukten A, Skurtveit S, Gossop M, Waal H, Stangeland P, Havnes I, et al. Engagement with opioid maintenance treatment and reductions in crime: a longitudinal national cohort study. Addiction. 2012;107(2):393-9.

6. Skeie I, Brekke M, Lindbaek M, Waal H. Somatic health among heroin addicts before and during opioid maintenance treatment: a retrospective cohort study. BMC Public Health. 2008;8(1).

7. Skeie I, Brekke M, Gossop M, Lindbaek M, Reinertsen E, Thoresen M, et al. Changes in somatic disease incidents during opioid maintenance treatment: results from a Norwegian cohort study. BMJ Open. 2011. https://doi.org/10. 1136/bmjopen-2011-000130.

8. Clausen T, Waal H, Thoresen M, Gossop M. Mortality among opiate users: opioid maintenance therapy, age and causes of death. Addiction. 2009; 104(8):1356-62.

9. Mattick RP, Breen C, Kimber J, Davoli M. Buprenorphine maintenance versus placebo or methadone maintenance for opioid dependence. Cochrane Database Syst Rev. (2014, 2):Cd002207. https://doi.org/10.1002/14651858. CD002207.pub4.

10. European monitoring Centre for Drugs and Drug Addiction. Treatment and care for older drug users. Luxembourg: European monitoring Centre for Drugs and Drug Addiction; 2010. Available from: http://www.emcdda. europa.eu/system/files/publications/580/EMCDDA_SI10_Ageing_242756.pdf. Accessed 10 September 2018.

11. Han B, Polydorou S, Ferris R, Blaum CS, Ross S, McNeely J. Demographic trends of adults in new York City opioid treatment programs-an aging population. Subst Use Misuse. 2015;50(13):1660-7.

12. European Monitoring Centre for Drugs and Drug Addiction. Statistical bulletin. EMCDDA. 2017. http://www.emcdda.europa.eu/data/stats2017/tdi_ en. Accessed 25 October 2018

13. Waal H, Bussesund K, Clausen T, Lillevold P, Skeie I. LAR Statusrapport 2017. LAR 20 år. Status, vurderinger og perspektiver. (Annual report 2017. OMT 20 years. Status, considerations and perspectives): University of Oslo, Oslo University Hospital 2018. Available from: https://www.med.uio.no/klinmed/ forskning/sentre/seraf/publikasjoner/rapporter/2018/seraf-rapport-nr-3-2018statusrapport-2017.pdf. Accessed 26 Aug 2018.

14. European Monitoring Centre for Drugs and Drug Addiction. Mortality among drug users in Europe: new and old challenges for public health. In: EMCDDA papers. EMCDDA. Luxembourg; 2015. http://www.emcdda.europa.eu/system/ files/publications/961/TDAU14010ENN.pdf. Accessed 26 Aug 2018.

15. Pierce M, Millar T, Robertson JR, Bird SM. Ageing opioid users' increased risk of methadone-specific death in the UK. Int J Drug Policy. 2018;55:121-7.

16. Gao L, Dimitropoulou P, Robertson JR, McTaggart S, Bennie M, Bird SM. Riskfactors for methadone-specific deaths in Scotland's methadone-prescription clients between 2009 and 2013. Drug Alcohol Depend. 2016;167:214-23.

17. Clausen T, Anchersen $\mathrm{K}$, Waal H. Mortality prior to, during and after opioid maintenance treatment (OMT): a national prospective cross-registry study. Drug Alcohol Depend. 2008;94(1-3):151-7.

18. LAR-forskriften. Forskrift om legemiddelassistert rehabilitering (Regulations concerning opioid maintenance treatment) 2009. Available from: http:// lovdata.no/forskrift/2009-12-18-1641. Accessed 10 April 2019.

19. Helsedirektoratet (Norwegian Directorate of Health). Nasjonal retningslinje for legemiddelassistert rehabilitering ved opioidavhengighet (National guidelines on opioid maintenance treatment ). Helsedirektoratet (Norwegian Directorate of Health), Oslo 2010. http://www.helsedirektoratet. no/publikasjoner/nasjonal-retningslinje-for-legemiddelassistert-rehabiliteringved-opioidavhengighet/Sider/default.aspx. Accessed 10 April 2019.

20. Folkehelseinstituttet (Norwegian Institute on Public Health). Dødsårsaksstatistikk (Cause of death statistics). Folkehelseinstituttet (Norwegian Institute of Public Health). 2010. https://www.fhi.no/en/hn/ health-registries/cause-of-death-registry/cause-of-death-registry-/. Accessed 1 April 2019.

21. World Health Organization. International statistical classifications of diseases and related health problems 10th revisions (ICD-10): WHO; 2016. Available from: https://icd.who.int/browse10/2016/en. Accessed 19 April 2019.

22. European Monitoring Centre for Drugs and Drug Addiction. Drug-related deaths (DRD) standard protocol, version 3.2 2009. EMCDDA, Lisbon. 2009. http://www.emcdda.europa.eu/html.cfm/index107404EN.html. Accessed 14 Jan 2019. 
23. Helsedirektoratet (Norwegian Directorate of Health). Norsk pasient register (Norwegian Patient Registry). Helsedirektoratet (Norwegian Directorate of Health), Oslo. 2019. https://helsedirektoratet.no/english/norwegian-patientregistry. Accessed 14 Jan 2019.

24. Charlson ME, Pompei P, Ales KL, MacKenzie CR. A new method of classifying prognostic comorbidity in longitudinal studies: development and validation. J Chronic Dis. 1987;40(5):373-83.

25. Quan H, Sundararajan V, Halfon P, Fong A, Burnand B, Luthi JC, et al. Coding algorithms for defining comorbidities in ICD-9-CM and ICD-10 administrative data. Med Care. 2005:43(11):1130-9.

26. Kirkwood BR, Sterne JAC. Essential medical statistics. Malden: Blackwell; 2003.

27. Islam MM, Taylor A, Smyth C, Day CA. General health of opioid substitution therapy clients. Intern Med J. 2013;43(12):1335-8.

28. Maruyama A, Macdonald S, Borycki E, Zhao J. Hypertension, chronic obstructive pulmonary disease, diabetes and depression among older methadone maintenance patients in British Columbia. Drug Alcohol Rev. 2013;32(4):412-8.

29. Rosen D, Smith ML, Reynolds CF, 3rd. The prevalence of mental and physical health disorders among older methadone patients. Am J Geriatr Psychiatry 2008;16(6):488-497.

30. Swart A, Burns L, Mao L, Grulich AE, Amin J, O'Connell DL, et al. The importance of blood-borne viruses in elevated cancer risk among opioiddependent people: a population-based cohort study. BMJ Open. 2012;2(5)

31. Randall D, Degenhardt L, Vajdic CM, Burns L, Hall WD, Law M, et al. Increasing cancer mortality among opioid-dependent persons in Australia: a new public health challenge for a disadvantaged population. Aust N Z J Public Health. 2011;35(3):220-5.

32. Gao YH, Guan WJ, Liu Q, Wang HQ, Zhu YN, Chen RC, et al. Impact of COPD and emphysema on survival of patients with lung cancer: a meta-analysis of observational studies. Respirology. 2016;21(2):269-79.

33. Mouronte-Roibas C, Leiro-Fernandez V, Fernandez-Villar A, Botana-Rial M, Ramos-Hernandez C, Ruano-Ravina A. COPD, emphysema and the onset of lung cancer. A systematic review. Cancer Lett. 2016;382(2):240-4.

34. European Monitoring Centre for Drugs and Drug Addiction. Hepatitis C among drug users in Europe: epidemiology, treatment and prevention. Luxembourg: EMCDDA; 2016. Available from: http://www.emcdda.europa. eu/system/files/publications/2953/TDXD16002ENN final_web.pdf. Accessed 10 April 2019

35. Larney S, Peacock A, Mathers BM, Hickman M, Degenhardt L. A systematic review of injecting-related injury and disease among people who inject drugs. Drug Alcohol Depend. 2017;171:39-49.

36. Harris M, Brathwaite R, Scott J, Gilchrist G, Ciccarone D, Hope V, et al. Drawing attention to a neglected injecting-related harm: a systematic review of AA amyloidosis among people who inject drugs. Addiction. 2018; 113(10):1790-801.

37. Manner I, Sagedal S, Roger M, Os I. Renal amyloidosis in intravenous heroin addicts with nephrotic syndrome and renal failure. Clin Nephrol. 2009;72(3): 224-8.

38. Clausen T. Mortality is reduced while on opiate maintenance treatment, but there is a temporary increase in mortality immediately after starting and stopping treatment, a finding that may vary by setting. Evid Based Med. 2011;16(3):94-5.

39. Pirnay S, Borron SW, Giudicelli CP, Tourneau J, Baud FJ, Ricordel I. A critical review of the causes of death among post-mortem toxicological investigations: analysis of 34 buprenorphine-associated and 35 methadoneassociated deaths. Addiction. 2004;99(8):978-88.

40. Leece P, Cavacuiti C, Macdonald EM, Gomes T, Kahan M, Srivastava A, et al. Predictors of opioid-related death during methadone therapy. J Subst Abus Treat. 2015;57:30-5.

41. McCowan C, Kidd B, Fahey T. Factors associated with mortality in Scottish patients receiving methadone in primary care: retrospective cohort study. BMJ. 2009;338:b2225

42. Kelty $E$, Hulse G. Fatal and non-fatal opioid overdose in opioid dependent patients treated with methadone, buprenorphine or implant naltrexone. Int J Drug Policy. 2017:46:54-60.

43. Xu X, Mishra GD, Jones M. Evidence on multimorbidity from definition to intervention: an overview of systematic reviews. Ageing Res Rev. 2017;37: 53-68.

44. Arnold-Reed DE, Brett T, Troeung L, O'Neill J, Backhouse R, Bulsara MK. Multimorbidity in patients enrolled in a community-based methadone maintenance treatment programme delivered through primary care. $J$ Comorb. 2014;4:46-54.

45. O'Toole J, Hambly R, Cox AM, O'Shea B, Darker C. Methadone-maintained patients in primary care have higher rates of chronic disease and multimorbidity, and use health services more intensively than matched controls. Eur J Gen Pract. 2014;20(4):275-80.

46. Madah-Amiri D, Clausen T, Lobmaier P. Rapid widespread distribution of intranasal naloxone for overdose prevention. Drug Alcohol Depend. 2017; 173:17-23.

47. Helsedirektoratet (Norwegian Directorate of Health). Nasjonal overdosestrategi 2019-2022 (National strategy for overdose prevention 2019-2022), Helsedirektoratet (Norwegian Directorate of Health); 2019. Available from: https://helsedirektoratet.no/publikasjoner/Nasjonaloverdosestrategi-20192022.pdf. Accessed 24 April 2019.

48. Guydish J, Passalacqua E, Pagano A, Martínez C, Le T, Chun J, et al. An international systematic review of smoking prevalence in addiction treatment. Addiction. 2016;111(2):220-30.

49. Zirakzadeh A, Shuman C, Stauter E, Hays JT, Ebbert JO. Cigarette smoking in methadone maintained patients: an up-to-date review. Curr Drug Abuse Rev. 2013:6(1):77-84.

\section{Publisher's Note}

Springer Nature remains neutral with regard to jurisdictional claims in published maps and institutional affiliations.
Ready to submit your research? Choose BMC and benefit from:

- fast, convenient online submission

- thorough peer review by experienced researchers in your field

- rapid publication on acceptance

- support for research data, including large and complex data types

- gold Open Access which fosters wider collaboration and increased citations

- maximum visibility for your research: over $100 \mathrm{M}$ website views per year

At BMC, research is always in progress.

Learn more biomedcentral.com/submissions 